
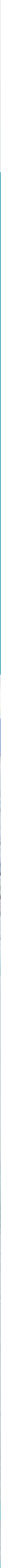

edpsciences 


\section{Dans la même collection :}

La valse des continents, P. De Wever et F. Duranthon, 2015, ISBN :

978-2-7598-1183-0.

\section{COLLECTION « LA TERRE À PORTÉE DE MAIN » DIRIGÉE PAR PATRICK DE WEVER}

Cette collection, dont les textes sont ponctués d'anecdotes, de petites questions et richement illustrés, est destinée à un très large public. Elle a pour vocation de présenter et de donner des notions très abordables en géologie sur les phénomènes et constituants de notre planète.

\section{Imprimé en France}

ISBN : 978-2-7598-1189-2

Tous droits de traduction, d'adaptation et de reproduction par tous procédés, réservés pour tous pays. La loi du 11 mars 1957 n'autorisant, aux termes des alinéas 2 et 3 de l'article 41, d'une part, que les « copies ou reproductions strictement réservées à l'usage privé du copiste et non destinées à une utilisation collective », et d'autre part, que les analyses et les courtes citations dans un but d'exemple et d'illustration, « toute représentation intégrale, ou partielle, faite sans le consentement de l'auteur ou de ses ayants droit ou ayants cause est illicite » (alinéa $1^{\text {er }}$ de l'article 40). Cette représentation ou reproduction, par quelque procédé que ce soit, constituerait donc une contrefaçon sanctionnée par les articles 425 et suivants du code pénal.

(C) EDP Sciences 2015 